Article

\title{
How to Deliver Open Sustainable Innovation: An Integrated Approach for a Sustainable Marketable Product
}

\author{
Francesco Cappa ${ }^{1,2, *}$, Fausto Del Sette ${ }^{3}$, Darren Hayes ${ }^{3,4}$ and Federica Rosso ${ }^{5, *}$ \\ 1 Department of Business and Management, LUISS Guido Carli University, Viale Romania 32, \\ 00197 Roma, Italy \\ 2 School of Engineering (DEIM), Tuscia University, Via S. Camillo de Lellis, 01100 Viterbo, Italy \\ 3 Dipartimento di Ingegneria Meccanica e Aerospaziale, Sapienza Università di Roma, Via Eudossiana 18, \\ 00184 Roma, Italy; fausto.delsette@uniroma1.it \\ 4 Seidenberg School of Computer Science \& Information Systems, Pace University, One Pace Plaza, New York, \\ NY 10038, USA; dhayes@pace.edu \\ 5 Dipartimento di Ingegneria Civile Edile e Architettura, Sapienza Università di Roma, Via Eudossiana 18, \\ 00184 Roma, Italy \\ * Correspondence: fcappa@luiss.it (F.C.); federica.rosso@uniroma1.it (F.R.); Tel.: +39-064-458-5162 (F.R.)
}

Academic Editors: Francesco Asdrubali and Pietro Buzzini

Received: 15 August 2016; Accepted: 14 December 2016; Published: 20 December 2016

\begin{abstract}
The adoption of open innovation and peer production, powered by 3D printing technology, is transforming traditional manufacturing methods towards a "third industrial revolution". The purpose of this research is to provide empirical evidence for an integrated approach, based on collaborative product development and peer production, combined with $3 \mathrm{D}$ printing, to deliver more sustainable, yet competitive, marketable products. In particular, this experimental study is conducted in the context of mobile forensics, an emerging market where limited expensive products exist and alternative solutions are needed. The technical viability and economic feasibility of the prototype developed in this research validate the proposed integrated approach, which could be a game-changer in the field of mobile forensics, as well as in other sectors. The sustainability improvements with this approach are a reduction of the total cost, thereby making it affordable for lower income users, and a decrease in energy consumption and pollutant emissions. The validated integrated approach offers start-up opportunities to develop and deliver more sustainable, marketable products, towards the paradigm of Open Sustainable Innovation. While the device developed and tested in this research has similar features to existing products, the methodology, implementation, and motivation are original.
\end{abstract}

Keywords: peer production; collaborative product development; open innovation; sustainability; 3D printing; open sustainable innovation; mobile forensics

\section{Introduction}

The recent trend of producing small quantities of custom designed and low cost finished goods comes from the model of mass customization, as postulated in the "think global and produce local" concept [1]. The increasingly popular means to better prepare for this novel trend are (i) open approach to hardware and software development; (ii) peer production, and (iii) distributed 3D printer manufacturing $[2,3]$.

The open innovation (OI) concept has changed the traditional, vertically-integrated mode for internally developed output, to achieve a new paradigm of innovation based on collaboration with several actors from outside the firm boundaries [4-12]. There are different partners that can be involved in OI practices, such as suppliers, universities, non-profit organization and other 
firms [13]. Recently, the advances in information technology facilitated the involvement of dispersed individuals by overcoming geographical, social, and physical barriers [14,15]. In this way, it is possible to exploit the "crowd wisdom" that arises from heterogeneous mindsets and knowledge diversity [16-20]. Collaboration amongst different people to develop the final product means that the distinctions between manufacturer and customer are disappearing, thereby building new collaborative networks [21,22]. Actually, this cooperation is understood to be an effective mechanism for increasing innovation efficiency and creativity $[4,23]$. OI can be applied to all of the product development stages, from hardware and software design to the production phase [24-26]. In this vein, hardware and software development can be realized and continuously updated thanks to the collaborative work of researchers and volunteers interacting online [27].

Peer production is intended as a collaborative activity aimed at sharing productive goals [28]. This productive methodology is based on self-organized communities, which easily interact together thanks to information technology advancements and cooperation to realize a final product. Towards this end, recent advances in 3D printing technology have made the production of components possible with commercially available desktop 3D printers [29], which are able to fabricate goods with custom shapes and colors [30]. Thus, people can network online for the ideation and the design of the product, and subsequently fabricate and assemble it locally.

$3 \mathrm{D}$ printing is a growing manufacturing technology that allows the design and fabrication of products or components directly from a computer connected to a 3D printer, by following successive steps [31]. First, the design is developed by means of a Computer Aided Design (CAD) 3D model; subsequently, it is converted to a Standard Triangulation Language (STL) format; then the file is transferred to a prototyping system, generally referred to as Computer Aided Manufacturing (CAM), where the structure is divided into layers. Finally, it is sent for fabrication to a desktop 3D printer. Thanks to 3D printing the production stage nowadays can easily enhance customers customization requirements [32]. Additionally, 3D printing is also able to unlock "latent entrepreneurship", as new opportunities are emerging to enter the market and bypass the barriers to entry, such as initial capital investment, mass production requirements for cost reductions, prototyping costs, and transportation and distribution systems [33]. In particular, the adoption of 3D printing and peer production allows (i) a reduction in supply chain management efforts; (ii) the recycling of wasted materials; (iii) the absence of costly tools, molds, or punches; and (iv) the elimination of inventory, as the production happens just in time [34]. Therefore, even if initially used for prototyping, 3D printing is nowadays increasingly employed for the final product realization of small production volumes [35]. Markets show that the annual sales growth rate of the 3D printing manufacturing sector was $+24 \%$ in 2010 , where $20 \%$ of the products were not prototypes, but real products [36], and the sector is expected to grow further in the coming years [35].

Nowadays, companies need not only to capture business opportunities and bring value to customers, but they must also provide social outcomes for the welfare of the public $[37,38]$. Actually, business strategies and regulations increasingly demand firms to enhance sustainability in addition to pursuing their traditional production criteria (i.e., economic feasibility, technical viability, and customer requirements) [39-41]. In order for products or services to be more sustainable, they must simultaneously benefit three main pillars: economy, society, and environment [39,42]. The profound shift in manufacturing, from remote factories to local 3D printing and peer production, in addition to product development, through collaboration parties outside the organization's boundaries, can help in the achievement of improved sustainability [43,44]. Therefore, the integrated approach herein described is intended to generate innovative, sustainable, marketable products by exploiting the open innovation paradigm and peer production with 3D printing, in an effort to achieve Open Sustainable Innovation (OSI) [45].

The adoption of open innovation and peer production powered by 3D printing technology is transforming traditional manufacturing methods towards a "third industrial revolution" [34]. Actually, low cost customization for everyone is favored by these methodologies, and will provide enormous 
value to the "commons" [46]. In particular, the research question we addressed in this paper is: can peer production, coupled with 3D printing and collaborative hardware and software development, be adopted in an integrated approach to deliver cheaper and more sustainable marketable products? To this end, we experimentally validate the development of a prototype, called Cellintel, for professional mobile forensics. Cellintel is a tool for extracting digital evidence from mobile devices during private and public investigations, and has the ability to compete with existing market competitors. Thus, the objective of this research is to demonstrate that the use of the integrated approach makes it possible to realize a product that is cheaper, more widely available, more sustainable than traditional manufacturing processes, and economically profitable in the mobile forensics sector.

The remainder of the paper is structured as follows. In Section 2, we introduce the field in which we tested the product development and where it will operate (i.e., mobile forensics). In Section 3, we provide an overview of the integrated approach, with details about the hardware and software components and related sustainability implications. In Section 4, we report field-testing results for the prototype. Section 5 provides an analysis of the product's economic feasibility. Section 6 details the limitations of the research and, finally, Section 7 addresses final thoughts and conclusions about our findings and possible future research.

\section{Experimental Context: Mobile Forensics}

Over the past twenty years, we have experienced exponential growth in mobile communications; the number of mobile phone subscribers has recently been estimated to be in excess of five billion, with a notable increase in sales in developing countries [47,48]. Mobile technologies have become an integral and pervasive part of common life, thanks to the increasing power, functionality, and ability to collect and share large quantities of data from such small devices [49].

Unfortunately, the propensity for criminals to use mobile phones to conduct their nefarious activities has also increased dramatically and, therefore, these devices have become even more valuable sources of evidence due to the incredible amount of information stored internally [50]. In particular, with the integration of highly developed communication features and with the increasing capacity in data storage and functionality, the distinction between mobile phones and personal computers has become blurred. Therefore, mobile device forensics is critical in every type of investigation today. In recent years, researchers and practitioners alike understood the importance of mobile devices as a fundamental source of digital evidence, which can be essential in capturing critical information to prosecute a suspect $[51,52]$.

This approach lies in the so-called digital forensics sector defined as: "The use of scientifically derived and proven methods toward the preservation, collection, validation, identification, analysis, interpretation, documentation and presentation of digital evidence derived from digital sources for the purpose of facilitating or furthering the reconstruction of events found to be criminal, or helping to anticipate unauthorized actions shown to be disruptive to planned operations" [53]. The concept of mobile forensics involves forensic imaging, which is the creation of a bit-for-bit copy of mobile device memory for examination during an investigation.

There are few investigative solutions, which are commercially available for mobile forensics, based on heterogeneous design criteria. Some of the most notable solutions include Paraben's Device seizure [54], Oxygen Forensics Suite [55], and Cellebrite's UFED [56], which extract data from the devices via a Universal Series Bus (USB) connection. The initial price, subsequent maintenance costs, large dimensions, and sizeable weight are common with all of these forensic technologies, while there is an increasing need for mobile forensics capabilities (i.e., see the 2016 Apple-FBI diatribe where the intelligence agency sought to compel Apple to gain access to terrorist's iPhone) [57]. The main incumbent in this sector, in terms of product maturity and market share, is Cellebrite with its UFED. Their product retails for approximately $\$ 20,000$, and comes with an annual maintenance commitment of approximately $\$ 3000$. Despite these high costs, the product can be found in numerous investigation departments. The unit is portable, but still heavy and cumbersome to be considered portable for 
professional activities. In addition, the limited selection of mobile forensics solutions means that prices are expected to remain high for the foreseeable future.

Therefore, mobile forensics represents a relevant field to empirically test the integrated approach proposed in this research. Actually, the sector does not have large production volume, which is a suitable characteristic for our production methodology, but it is growing globally, giving good scalability opportunities for start-ups. The incumbents are few and sell expensive solutions, thereby leaving opportunities for new entrants with different production techniques. This sector involves hardware and software development, thus the proposed integrated approach can benefit both fields of expertise.

\section{A New Integrated Approach for Product Development}

The potential to develop and offer a state-of-the-art device for mobile forensics, at a lower price and with smaller dimensions, is attractive. Offering a cheaper device is an objective not just for economic reasons in an effort to challenge existing competitors, but also to address the needs of private investigators and smaller institutions that cannot afford expensive solutions. Additionally, an easier and faster production process will facilitate the global distribution of these devices. Therefore, while the design of the hardware and software take place online, through the collaboration of loosely affiliated collaborators, who are directed by the researchers through an open innovation approach (i.e., recently defined "crowdsourcing" [58]), the production of the final product can be achieved by local branches worldwide. Utilizing this production and distribution approach, the product also promotes environmental sustainability, as it is able to reduce energy supply usage and $\mathrm{CO}_{2}$ emissions when compared to traditional production methodologies [35]. Finally, to make field investigations easier, the device must be easy to use and portable.

Therefore, in this study we focused on developing a mobile forensics imaging device, with improved field usability and customer accessibility, which was cheaper, environmentally sustainable, and economically feasible. The prototype described in this paper represents an example of OSI [45], as it is based on open innovation for worldwide development and assembly, while enhancing sustainability by (i) eliminating the inventory, transportation, and delivery costs; (ii) reducing the production costs and time while still generating profits and, finally; (iii) decreasing pollutant emissions by lowering energy consumption [35].

In order to achieve these objectives, the following steps have been undertaken: (i) offering an open approach to software development and hardware design, by involving international students from different fields of study in collaboration with the researchers; (ii) exploiting peer production based on 3D printing and off-the-shelf components to assemble the product; (iii) performing empirical testing and economic simulation to validate this new compact, portable device developed for this research. This study offers empirical evidence for the successful implementation of this new integrated approach in the field of mobile forensics, which could be generalized and applied to other sectors.

\subsection{Hardware Prototype}

In this section, the hardware design is described and the electronic components are listed, in order to provide a comprehensive overview of the final product. The prototype is an electronic portable device that acquires and stores digital evidence. The device can image both Android and iOS devices, which account for $95 \%$ of the United States mobile operating system market share and $90 \%$ of European Union market share [59]. An open approach is used for both hardware and software design, in order to involve external partners in product development [27].

The electronic parts used were chosen among those readily available in the marketplace. The external case of the imager was produced with a 3D printer, and finally all of the components are manually assembled. In the following subsections, the prototype components are described, although the in-depth details were not disclosed as the aim of this research is to provide evidence of 
the possibility to enter the market with this new approach and, therefore, we are looking to effectively start-up a new venture and sell the product in the near future.

\subsubsection{Case Design and Production}

The prototype device was designed with several key characteristics in mind, which were: (i) lower cost; (ii) touchscreen; (iii) smaller than competitors; (iv) lighter than competitors; (v) easier to assemble; (vi) ability to connect to different mobile devices; and (vii) manually assembled. Thus, the adoption of 3D printing technology to produce the device allows a minimal initial investment for the production equipment, low unit cost, product portability, custom design, and ease of assembly. The project began with the acquisition of two desktop 3D printers, which were not excessively expensive, whose cost lies in the range of $\$ 3000$ to $\$ 10,000$. As the precision and the surface finishing of a 3D printer increase, the price rises too. The design of the casing was realized with 3D CAD (Figure 1).

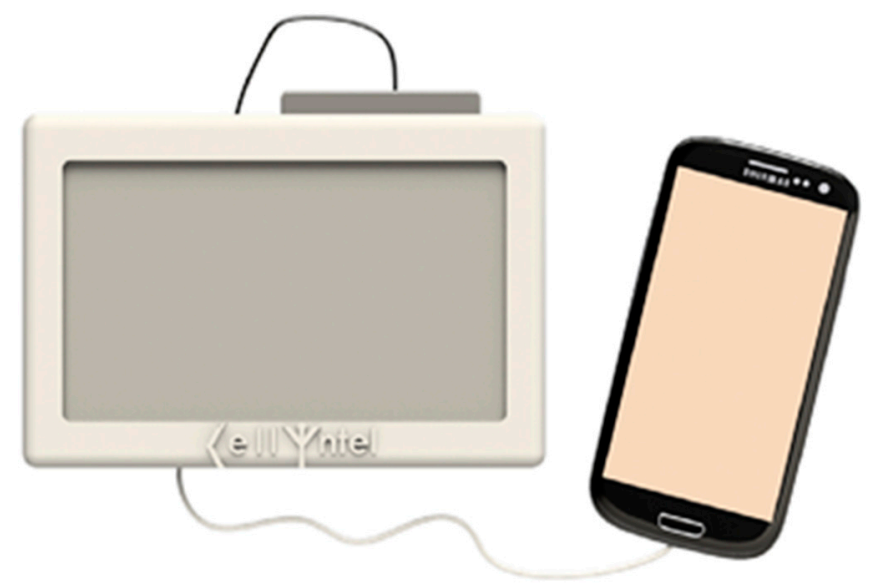

Figure 1. Computer aided design (CAD) rendering of the Cellintel prototype connected to a mobile device.

Given the goal of peer production, screws and bolts were avoided, and the assembly of the parts was designed for manual interlocking, by applying a small force. Therefore, the product can be manufactured and assembled in different locations and by different individuals without any specialized training. The 3D printed parts for the prototype case are comprised of: (i) a case to house electronic components and batteries, with openings designed specifically for connectors and board; (ii) the second part is mounted on top of the previous part to house the liquid crystal display (LCD) screen; and (iii) the third part locks the LCD screen into place.

The desktop software Solidworks (release 2013, Dassault Systèmes, Velizy-Villacoublay, France) was employed to create the file used by the $3 \mathrm{D}$ printer. The software was also able to provide information regarding the cost of plastic used and the time required to complete each unit. In Table 1, the overall production cost, which also includes electricity costs based on an estimation of similar 3D-printed products in the USA [3,60], is listed for each component. The casing material is acrylonitrile butadiene styrene (ABS), a thermoplastic polymer typically used by 3D printers. The printer used for the first casing was a low-cost, $\$ 3000$, commercially available desktop solution (Makerbot Replicator 5th, Makerbot, New York, NY, USA). For the second casing prototype, another more expensive $(\$ 10,000)$ commercial 3D printer (S250 Tiertime, Tiertime, Beijing, China) was employed. These printers use the fuse deposition modeling (FDM) [61], an additive manufacturing process that works by laying down the plastic filament in layers, unwound from a coil and hot-extruded [62]. The printing outputs are the same in terms of functionality between the two solutions, but the second printer provides a superior precision level and a smoother surface finishing, more suitable for entering the market and for competing with the incumbents. 
Table 1. Costs for the 3D printed casing components for the Cellintel prototype.

\begin{tabular}{cccc}
\hline Components & Mass & Production Time & Cost \\
\hline Electronic box & $17 \mathrm{~g}$ & $4 \mathrm{~h}, 12 \mathrm{~m}$ & $\$ 3.40$ \\
LCD Screen box & $21.8 \mathrm{~g}$ & $2 \mathrm{~h}, 38 \mathrm{~m}$ & $\$ 2.56$ \\
Top of the box & $16.4 \mathrm{~g}$ & $2 \mathrm{~h}, 10 \mathrm{~m}$ & $\$ 2.14$ \\
Electricity costs & $55.2 \mathrm{~g}$ & & $\$ 0.03$ \\
Total & $\mathbf{5 5 . 2} \mathbf{g}$ & $\mathbf{9 h}$ & $\mathbf{\$ 8 . 1 3}$ \\
\hline
\end{tabular}

\subsubsection{Prototype Electronics}

The electronic parts were housed in the casing produced with the 3D printing methodology. To keep costs low, the device was built around off the shelf components that are cheap and easily available on the market. The average prices of the electronics components are listed in Table 2.

Table 2. Costs of the off the shelf electronic components for the Cellintel prototype.

\begin{tabular}{cc}
\hline Components & Cost \\
\hline LCD screen & $\$ 55.99$ \\
Solid state drive (SSD) 2.5” & $\$ 85.99$ \\
Motherboard & $\$ 49.89$ \\
3D printed casing & $\$ 8.13$ \\
Total & $\mathbf{\$ 2 0 0}$ \\
\hline
\end{tabular}

\subsection{Software Prototype}

The novel device developed in this research, operates using a Debian Linux build operating system (kernel 3.4.90). An interface, written in Java programming language, runs on top of the operating system, providing the user a simple one-click method to execute programs and scripts installed in the device, which automates the process of evidence acquisition. The choice of Linux, an open source operating system, facilitates the open innovation approach to software development, as many communities are active in providing drivers and access to the mobile devices. The in-house developed software was created by a community of student volunteers working together with researchers, a cooperation that facilitates the implementation of future updates, who utilize open source code from community platforms, such as GitHub [63].

The starting point for the prototype's software was in-house developed software, used to extract data from Android and iOS devices. The community at large would contribute to updates. The user interface, created in Java, was designed to be user-friendly, thereby appealing to more users. The user interface was designed with touch screen in mind, which was easy to use.

\subsection{Sustainability Implications}

The concept of sustainability requires "development that meets the needs of the present without compromising the ability of future generations to meet their own needs" [64]. The changing needs of customers and the introduction of new laws internationally have increased the demand for more sustainable products. More than ever, firms are engaged in redesigning their products and services towards sustainability [39-41]. Innovative products and services should comply with traditional specifications, in terms of quality and technical standards, as well as with sustainability requirements [39].

The definition of sustainability is broad and covers economic, social, and environmental concerns, which are considered to be the three "overlapping dimensions of sustainability" [65]. Therefore, to foster sustainability and to benefit all stakeholders, innovations must be effective in simultaneously benefiting the economy, society, and the environment $[39,42]$. The integrated approach described in this study fulfills these three dimensions of sustainability by reducing the overall cost (and purchase price), energy consumption, and pollutant emissions [35]. Thus, society benefits from lower priced products with 
greater accessibility; the economy is enhanced by bringing to market profitable products and facilitating new ventures; and, finally, the environment is safeguarded by lowering energy consumption and pollution $[42,66]$. More specifically, the integrated approach outlined in this research allows products to be manufactured locally thanks to $3 \mathrm{D}$ printers and peer production. As a result, raw materials, transportation costs, inventory stock, and wasted materials are significantly reduced [67]. Indeed, production costs, energy usage, and $\mathrm{CO}_{2}$ emissions can be reduced on average by $25 \%, 30 \%$, and $30 \%$, respectively, when compared to traditional production techniques, as demonstrated by previous research [35]. More specifically, the potential savings realized by 3D printing and peer production, in terms of costs and $\mathrm{CO}_{2}$ emissions, are estimated to be in the range of \$170-\$579 billion USD and 130-525 Mt of $\mathrm{CO}_{2}$, respectively, by 2025 [35]. These savings, in terms of lower energy usage and pollutant emissions, positively impact both the environment and society, given the current global strategies against climate change [68-71]. In addition, reduced costs allow broader appeal, by offering the device at a lower price while still realizing profitability, as analyzed in Section 5 .

The ability to support all three pillars of sustainability (i.e., economical, societal, and environmental [39,42]), while also pursuing business objectives, means that the innovative product realized through our proposed integrated approach represents a successful implementation of the OSI paradigm [45].

\section{Empirical Testing}

The empirical testing performed during the study showed positive results in producing the prototype using the aforementioned techniques. The prototype has similar functionality and improved usability when compared to rivals. After the collaborative hardware and software design described in the previous sections, the Cellintel prototype was produced with a S250 Tiertime 3D printer and was then manually assembled. Subsequently, the software was installed on the device (Figure 2).

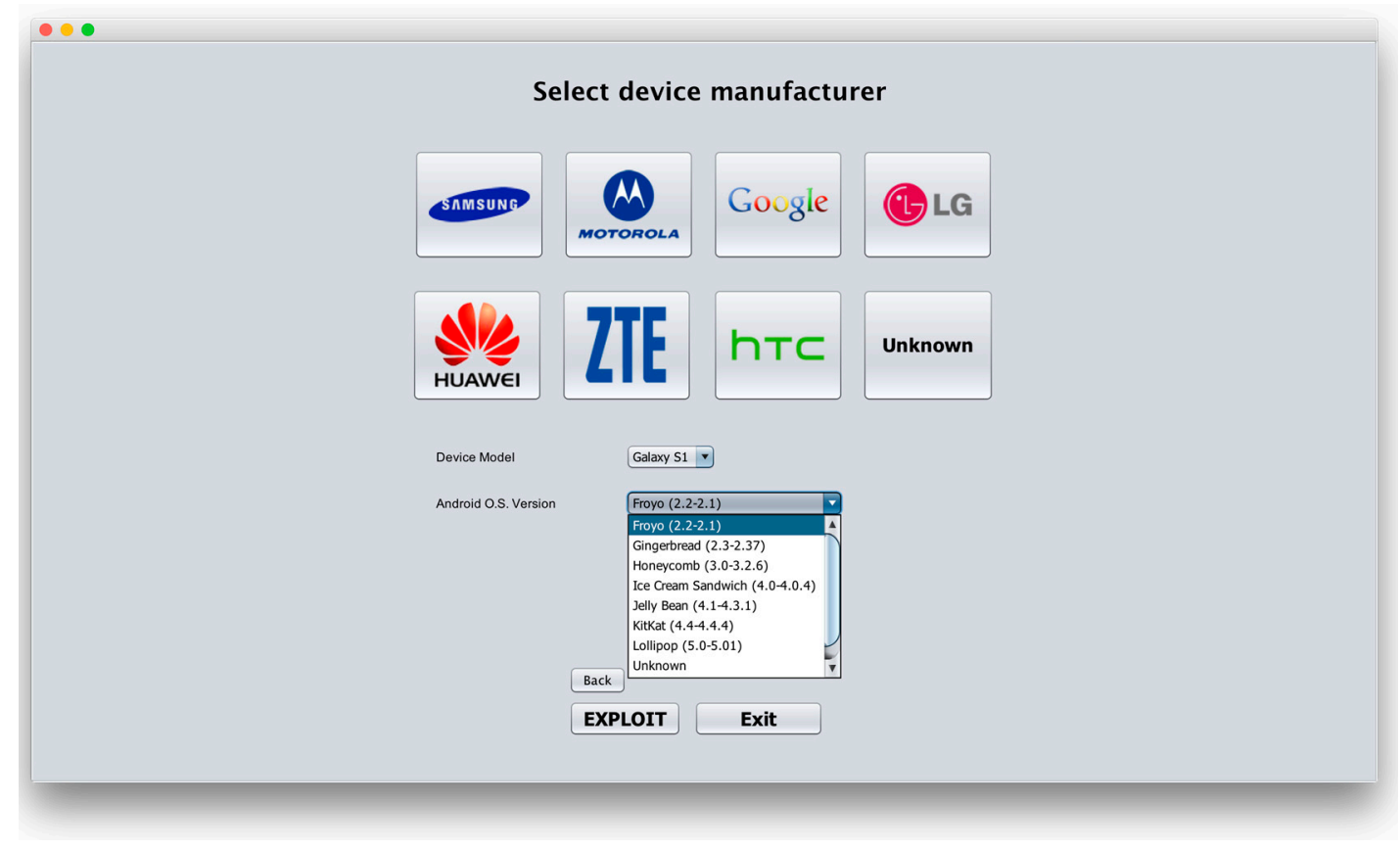

Figure 2. Cellintel prototype user interface during data extraction of an Android smartphone.

The assembled prototype, consisting of the in-house produced 3D printed case and commercially available components, is displayed in Figure 3. 


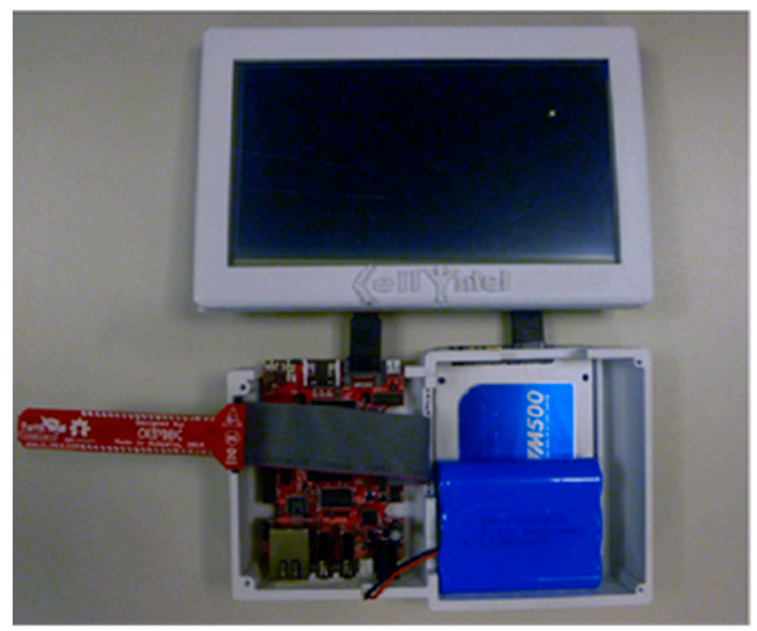

Figure 3. Cellintel prototype's components during the manual assembly: LCD screen, 3D printed screen case, battery, SSD hard disk drive, printed circuit board, cables for connections among components, and $3 \mathrm{D}$ printed base case.

Finally, data extractions for forensics investigations, performed with the prototype device Cellintel, were successful with both Android and iOS devices (Figure 4).

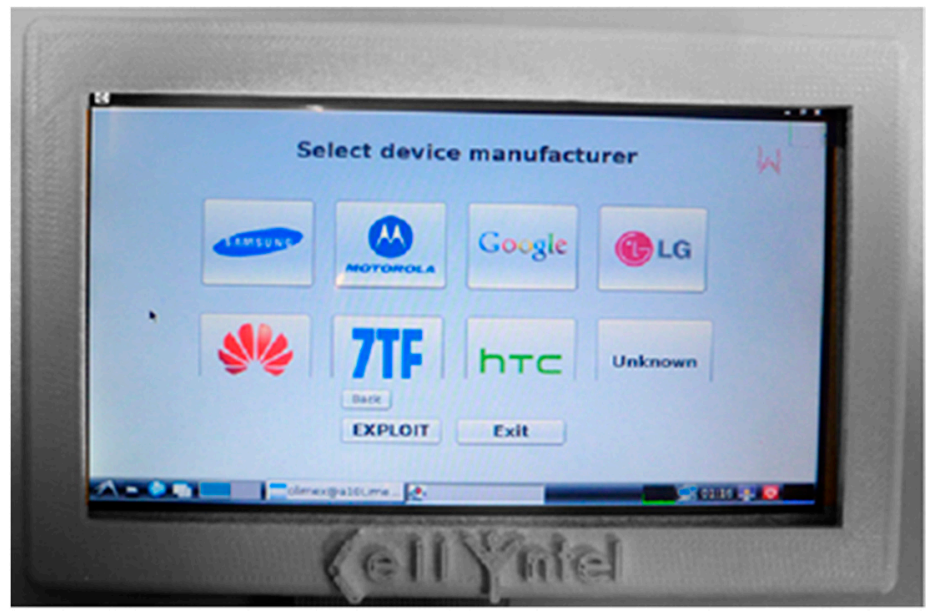

Figure 4. CellIntel assembled prototype in function: touch screen user interface during the choice of the device to be imaged.

\section{Economic Analysis}

The finished prototype demonstrated the technical viability of the proposed integrated approach, with the ability to deliver the same technical features of its main competitors. However, the objective of this research was not only the validation of a state-of-the-art mobile forensics imaging device, but also to demonstrate its economic feasibility while offering it at a drastically lower price compared to its competitors, while still maintaining a reasonable margin to start-up in the market. The supply chain is simplified, as all of the components are readily available on the market or can be 3D printed and manually assembled, and the value proposition for customers is to buy a cheaper and more sustainable product (as described in Section 3.3). The last aspect to be addressed is how the new venture can become profitable [44,72]. In order to assess the economic feasibility of this new product in the market, it is crucial for a new venture to perform a Net Present Value (NPV) analysis [73]. The inputs required to conduct a NPV analysis are (i) duration of the project; (ii) cost of capital; (iii) tax rate and, finally; 
(iv) free cash flows. All of the detailed assumptions and calculations are provided in the following paragraphs. In particular, the information used to calculate the free cash flow for each year of operation was: (i) revenues; (ii) costs of units sold; (iii) employees' wages; (iv) initial capital investment for the equipment; and its (v) amortization. All of the details are reported in the following paragraphs and are summarized in a Table 3.

With regards to the overall costs, we considered the main constituents of the total cost of ownership model [74-76]. The operating costs are divided into the cost of units sold, as the plastic and electricity cost per unit produced, and labor costs, as employees' wages. The logistics and transportation costs, which generally account for $15 \%$ of the overall costs [67], are avoided as all of the components are delivered or produced at local assembly stations. Moreover, there is no inventory cost due to the fact the production happens just in time. We considered an initial cost for the 3D printer with a conservative expected lifetime and amortization. Additionally, we also considered the opportunity cost of capital and the taxes for running the venture. Regarding the costs related to the software, the researchers involved in the project were already established software developers and they partially used code from open source software communities.

In our testing, we developed a durable and resilient prototype with both the Makerbot printer [77] and the S250 Tiertime printer [78], although differences in the surface finishing are noticeable and the latter one is consequently preferred for the final production. The time required for the production of our 3D printed toolbox is about eight hours, and one hour for the final assembly. Therefore, with one 3D printer, each day it is possible to produce two finished products, and approximately 40 units per month. The raw material for the 3D printer has an estimated cost of $\$ 8$, while the components costs $\$ 192$, for a total cost of $\$ 200$ to realize the final product, as reported in Table 2. In this research, we aimed to sell the product for a much lower unit price than the competitors' product, which is $\$ 999$ instead of $\$ 10,000$, on average. This price is significantly less than the competitors' prices, but it also allows a reasonable markup (i.e., the margin of revenues over costs) for starting a new venture.

Choosing to buy the most expensive 3D printer (the $\$ 10,000$ S250 Tiertime printer), as a result of a better surface finished casing, we estimated the break-even point for units sold, which tells us the amount of goods produced for which the NPV equals zero. The lifespan of the printer is supposed to be three years, which is a conservative estimate considering that the warranty period offered in Europe for this product is two years. Thus, the initial investment is equal to $\$ 10,000$, with an annual straight-line depreciation of $\$ 3333$. An appropriate cost of capital must be apportioned for an evaluation of the project with the NPV methodology, as described in $[79,80]$. We concur that the cost of capital for the computer service sector nowadays (updated to September 2015) in the USA, which represents our target market to deploy our product, is $7.64 \%$ [81] and the tax rate is $40 \%$.

Two simulations were performed to assess the required number of units to be produced and sold to achieve the break-even point. In the first scenario, hypothesizing an early start-up stage, where the creators can run the project without remuneration (i.e., no employees' wages), the break-even is reached by selling at least 7 units per year. Therefore, to achieve profitability the company must sell more than 7 units annually; after the 8th unit sold annually, the revenue will be sufficient to generate remuneration for the software and hardware developers and profits for the company. In our second scenario, simulating a more advanced start-up stage, three people work full-time on this project, operating in all of the firm's roles, earning an annual salary of $\$ 50,000$. In this scenario, the break-even point is reached with the production of 68 units per year (Table 3). Therefore, from the 69th unit produced onwards, the company will be generating a profit. According to a recent study [34], $3 \mathrm{D}$ printing is profitable for niche markets, like mobile forensics, where production runs in the range of 50 to 5000 units. Our research confirms this assertion. The break-even point of units sold represents a reasonable annual forecast, when initially focusing on the USA, because the potential consumer market size is expanding exponentially. Moreover, by reducing the price the number of potential users and purchasers will increase. The production approach postulated in this research facilitates scalability and global reach. 
Table 3. Net present value analysis for the commercialization of Cellintel, in the hypothesis of three waged employees. Reported below is the break-even point of units sold. Parentheses indicate negative values.

\begin{tabular}{|c|c|c|c|c|}
\hline Units & \multicolumn{4}{|c|}{68} \\
\hline Cost of capital & \multicolumn{4}{|c|}{$7.64 \%$} \\
\hline Taxes & \multicolumn{4}{|c|}{$40 \%$} \\
\hline Price & \multicolumn{4}{|c|}{$\$ 999$} \\
\hline Cost & \multicolumn{4}{|c|}{$\$ 200$} \\
\hline Year & 0 & $1 \mathrm{st}$ & 2nd & $3 \mathrm{rd}$ \\
\hline Revenues & & $\$ 67,932$ & $\$ 67,932$ & $\$ 67,932$ \\
\hline Cost of unit sold & & $\$(13,600)$ & $\$(13,600)$ & $\$(13,600)$ \\
\hline Salary costs & & $\$(50,000)$ & $\$(50,000)$ & $\$(50,000)$ \\
\hline Depreciation & & $\$(3333.33)$ & $\$(3333.33)$ & $\$(3333.33)$ \\
\hline Earnings Before taxes & & $\$ 998.66$ & $\$ 998.66$ & $\$ 998.66$ \\
\hline Taxes & & $\$(399.33)$ & $\$(399.33)$ & $\$(399.33)$ \\
\hline Depreciation added back & & $\$ 3333.33$ & $\$ 3333.33$ & $\$ 3333.33$ \\
\hline Initial capital expenditure & $(\$ 10,000)$ & & & \\
\hline Free cash flow to operations & $(\$ 10,000)$ & $\$ 3932.53$ & $\$ 3932.53$ & $\$ 3932.53$ \\
\hline Net Present Value & $\$ 200.71$ & & & \\
\hline
\end{tabular}

\section{Limitations}

With the aforementioned integrated approach, we evaluated the economic and practical feasibility of a cheaper and sustainable mobile forensics imaging device, which is ready to enter the marketplace for general consumption. However, some limitations impact our prototype. Understandably, the Cellintel prototype developed for this research cannot support many inexpensive phones models, which are running less reputable mobile operating systems. Nevertheless, this functional limitation also exists in well-known mobile device imagers. Additionally, there is no support for Blackphones or BlackBerry, although their market share is dwindling. Additionally, Windows smartphones cannot be imaged using traditional methods (i.e., through a USB cable) [82-84].

Moreover, the community of researchers and students, employed on this project, must continually maintain and update the software and the hardware for the device to ensure support for new mobile devices coming to market.

Finally, as this study presents the first empirical evidence of a successful application of our integrated approach for innovative products, the application of this methodology to other sectors is critical for increased generalizability of the outcomes.

\section{Conclusions}

This paper provides empirical evidence for the technical viability, economic feasibility, and enhanced sustainability of a product developed with an integrated approach based on open innovation and peer production with the use of 3D printing. The relevance of the study is in demonstrating the benefits of utilizing these three growing trends $[24,29,30,32,34,35]$, when adopted in concert, in terms of improved sustainability and start-up opportunities. Empirical testing of this integrated approach was conducted in the mobile forensics sector. Because mobile forensics tools are comprised of integrated software and hardware, both hardware and software can benefit from the aforementioned approach. Additionally, mobile forensics is a suitable sector for testing these production techniques, as it is a niche market with low production volumes. Moreover, the market for mobile forensics tools is growing for both private and public sectors globally. Consequently, there is potential for global scalability of this product. The incumbents offer expensive products, yet smaller law enforcement agencies are in need of cheaper and more portable solutions. This research offers the opportunity to provide the market with cheaper products. Therefore, while more expensive devices with similar features already exist in the mobile forensics market, the methodology, implementation, and motivation of this research are original. 
More specifically, the open approach is used for the design of hardware and software components, so that individuals can collaborate with the researchers, via the Web, and develop a new product. The use of 3D printing technology and peer production enables the device to be produced locally, thereby significantly reducing total costs and purchase price, while lowering energy consumption and decreasing pollutant emissions, and ultimately promoting sustainability $[37,85]$. Thus, this methodology addresses the current environmental and social needs to reduce energy consumption and emissions, which are fundamental global goals for all sectors, whether mandated or incentivized [68]. It is crucial for start-ups to recognize the number of required units to be sold annually to be competitive and exceed the break-even point, and this is why we used the NPV methodology. The estimated number of units sold per year is a reasonable amount for the growing mobile forensics market. We have provided evidence for the economic feasibility of the product with this integrated approach, while offering the product for a lower purchase price in furtherance of economic sustainability. Finally, the experimental testing that was conducted on our prototype demonstrated the technical viability of the integrated approach to deliver a state-of-the-art product.

Considering the aforementioned results, this research provides empirical evidence for the successful implementation of the OSI paradigm, while addressing factors that include sustainability, technical viability, and economic feasibility. The prototype developed in this study allows entrepreneurs to successfully begin a new venture while reducing the purchase price for consumers, and lowering energy usage and pollutants emissions. Therefore, it is possible to simultaneously promote the three facets of sustainability (i.e., economic, societal, and environmental), thereby benefiting all the stakeholders $[42,65,86]$.

The integrated approach proposed in this research could be a game-changing concept, not only in the mobile forensics context, but could also be tested in other niche sectors as a new standard to deliver cheaper products in a more sustainable way, while simultaneously being able to compete with market incumbents. Future research will be focused on small batch production and field-testing by practitioners in an effort to verify the efficacy of the mobile forensics imager developed in this research. These professionals would be subsequently surveyed and their feedback will be used to improve the device. Moreover, in this research we carried out preliminary estimates of energy and emissions reductions. Once the product goes to market, further research will be conducted, utilizing Life Cycle Assessment, to quantify more precisely energy consumption and emissions reductions resulting from our integrated approach.

Acknowledgments: To conduct this research, Francesco Cappa and Federica Rosso were supported by the "Fondi addizionali per la ricerca" awarded by the Italian Minister of University "Ministero dell'Istruzione, dell'Università e della Ricerca"; Fausto Del Sette and Federica Rosso received funds from Honor Center of Italian Universities "H2CU"; Francesco Cappa was supported by grant \# PRIN 2010H37KAW received from the Italian Minister of University "Ministero dell'Istruzione, dell'Università e della Ricerca". The authors would like to gratefully acknowledge the use of Pace University's Computer Forensics Laboratory and James Ossipov for his collaboration in developing the mobile forensic imaging device. Additionally, our thanks go to Raffaele Oriani for useful suggestions and to Paolo Special for his support.

Author Contributions: The authors equally contributed to the development of this research.

Conflicts of Interest: The authors declare no conflict of interest. The founding sponsors had no role in the design of the study; in the collection, analyses, or interpretation of data; in the writing of the manuscript, and in the decision to publish the results.

\section{References}

1. Gershenfeld, N. How to Make Almost Anything. Foreign Aff. 2012, 91, 43-57.

2. Parvin, A. Architecture (and the other 99\%): Open-Source Architecture and Design Commons. Arch. Des. 2013, 83, 90-95. [CrossRef]

3. Wittbrodt, B.T.; Glover, A.G.; Laureto, J.; Anzalone, G.C.; Oppliger, D.; Irwin, J.L.; Pearce, J.M. Life-cycle economic analysis of distributed manufacturing with open-source 3-D printers. Mechatronics 2013, 23, 713-726. [CrossRef] 
4. Antikainen, M.; Mäkipää, M.; Ahonen, M. Motivating and supporting collaboration in open innovation. Eur. J. Innov. Manag. 2010, 13, 100-119. [CrossRef]

5. Carlsson, S.; Corvello, V.; Schroll, A.; Mild, A. Open innovation modes and the role of internal R\&D: An empirical study on open innovation adoption in Europe. Eur. J. Innov. Manag. 2011, 14, 475-495.

6. Enkel, E.; Gassmann, O.; Chesbrough, H. Open R\&D and open innovation: Exploring the phenomenon. RED Manag. 2009, 39, 311-316.

7. Helfat, C.E. Open Innovation: The new imperative for creating and profiting from technology. Acad. Manag. Perspect. 2006, 20, 86-88. [CrossRef]

8. Chesbrough, H.W. The Era of Open Innovation. MIT Sloan Manag. Rev. 2003, 44, 35-41.

9. Schwerdtner, W.; Siebert, R.; Busse, M.; Freisinger, U. Regional open innovation roadmapping: A new framework for innovation-based regional development. Sustainability 2015, 7, 2301-2321. [CrossRef]

10. Michelino, F.; Cammarano, A.; Lamberti, E.; Caputo, M. Knowledge domains, technological strategies and open innovation. J. Technol. Manag. Innov. 2015, 10, 50-78. [CrossRef]

11. West, J.; Salter, A.; Vanhaverbeke, W.; Chesbrough, H. Open innovation: The next decade. Res. Policy 2014, 43, 805-811. [CrossRef]

12. Cammarano, A.; Caputo, M.; Lamberti, E.; Michelino, F. R\&D collaboration strategies for innovation: An empirical study through social network analysis. Int. J. Innov. Technol. Manag. 2016, 14, 1740001.

13. Belderbos, R.; Carree, M.; Lokshin, B. Cooperative R\&D and firm performance. Res. Policy 2004, 33, 1477-1492.

14. Schemmann, B.; Herrmann, A.M.; Chappin, M.M.H.; Heimeriks, G.J. Crowdsourcing ideas: Involving ordinary users in the ideation phase of new product development. Res. Policy 2016, 45, 1145-1154. [CrossRef]

15. Cappa, F.; Laut, J.; Nov, O.; Giustiniano, L.; Porfiri, M. Activating social strategies: Face-to-face interaction in technology-mediated citizen science. J. Environ. Manag. 2016, 182, 374-384. [CrossRef] [PubMed]

16. Felin, T. Cosmologies of capability, markets and wisdom of crowds: Introduction and comparative agenda. Manag. Decis. Econ. 2012, 33, 283-294. [CrossRef]

17. Surowiecki, J. The Wisdom of Crowds. Am. J. Phys. 2005, 75, 336. [CrossRef]

18. Garcia Martinez, M.; Walton, B. The wisdom of crowds: The potential of online communities as a tool for data analysis. Technovation 2014, 34, 203-214. [CrossRef]

19. Sassenberg, K.; Moskowitz, G.B. Don't stereotype, think different! Overcoming automatic stereotype activation by mindset priming. J. Exp. Soc. Psychol. 2005, 41, 506-514. [CrossRef]

20. Acar, O.A.; van den Ende, J. Knowledge Distance, Cognitive-Search Processes, and Creativity: The Making of Winning Solutions in Science Contests. Psychol. Sci. 2016, 27, 692-699. [CrossRef] [PubMed]

21. Koch, C. Innovation networking between stability and political dynamics. Technovation 2004, 24, 729-739. [CrossRef]

22. Vujovic, S.; Ulhøi, J.P. Online innovation: The case of open source software development. Eur. J. Innov. Manag. 2008, 11, 142-156. [CrossRef]

23. Grimaldi, M.; Cricelli, L.; Rogo, F. A methodology to assess value creation in communities of innovation. J. Intellect. Cap. 2012, 13, 305-330. [CrossRef]

24. Moilanen, J.; Vadén, T. 3D printing community and emerging practices of peer production. First Monday 2013, 18, 8. [CrossRef]

25. Von Hippel, E. Democratizing innovation. J. Betr. 2005, 55, 63-78.

26. Von Hippel, E. Open user innovation. Handb. Econ. Innov. 2010, 1, 411-427.

27. Bonaccorsi, A.; Rossi, C. Why Open Source software can succeed. Res. Policy 2003, 32, 1243-1258. [CrossRef]

28. Benkler, Y.; Nissenbaum, H. Commons-based peer production and virtue. J. Political Philos. 2006, 14, $394-419$. [CrossRef]

29. Kostakis, V.; Papachristou, M. Commons-based peer production and digital fabrication: The case of a RepRap-based, Lego-built 3D printing-milling machine. Telemat. Inform. 2014, 31, 434-443. [CrossRef]

30. Espalin, D.; Muse, D.W.; MacDonald, E.; Wicker, R.B. 3D Printing multifunctionality: Structures with electronics. Int. J. Adv. Manuf. Technol. 2014, 72, 963-978. [CrossRef]

31. Mertz, L. New World of 3-D Printing Offers "Completely New Ways of Thinking". IEEE Pulse 2013, 4, 12-14. [PubMed]

32. Matias, E.; Rao, B. 3D printing: On its historical evolution and the implications for business. In Proceedings of the 2015 Portland International Conference on Management of Engineering and Technology (PICMET), Portland, OR, USA, 2-6 August 2015; pp. 551-558. 
33. Ratto, M.; Ree, R. Materializing information: 3D printing and social change. First Monday 2012, 17. [CrossRef]

34. Berman, B. 3-D printing: The new industrial revolution. Bus. Horiz. 2012, 55, 155-162. [CrossRef]

35. Gebler, M.; Schoot Uiterkamp, A.J.M.; Visser, C. A global sustainability perspective on 3D printing technologies. Energy Policy 2014, 74, 158-167. [CrossRef]

36. Wohlers, T. Wohlers Report 2014. 3D Printing and Additive Manufacturing State of the Industry; Wohlers Associate: Fort Collins, CO, USA, 2014.

37. Cho, C.; Lee, S. How firms can get ideas from users for sustainable business innovation. Sustainability 2015, 7, 16039-16059. [CrossRef]

38. Pinelli, M.; Maiolini, R. Strategies for Sustainable Development: Organizational Motivations, Stakeholders' Expectations and Sustainability Agendas. Sustain. Dev. 2016, in press. [CrossRef]

39. Maxwell, D.; Van der Vorst, R. Developing sustainable products and services. J. Clean. Prod. 2003, 11, 883-895. [CrossRef]

40. Lubin, D.A.; Esty, D.C. Bridging the Sustainability Gap. MIT Sloan Manag. Rev. 2012, 55, 18-21.

41. Lubin, D.A.; Esty, D.C. The sustainability imperative. Harv. Bus. Rev. 2010, 88, 42-50.

42. Morelli, J. Environmental Sustainability: A Definition for Environmental Professionals. J. Environ. Sustain. 2011, 1, 1-27. [CrossRef]

43. Moreno, M.; Charnley, F. Can Re-Distributed Manufacturing and Digital Intelligence Enable a Regenerative Economy? An Integrative Literature Review; Springer: Berlin, Germany, 2016; pp. 563-575.

44. Boons, F.; Montalvo, C.; Quist, J.; Wagner, M. Sustainable innovation, business models and economic performance: An overview. J. Clean. Prod. 2013, 45, 1-8. [CrossRef]

45. Arcese, G.; Flammini, S.; Lucchetti, M.C.; Martucci, O. Open Sustainability Innovation in the Food Sector. World Sustain. Forum 2014, 7, 8067-8090.

46. Pearce, J.M. Quantifying the Value of Open Source Hard-ware Development. Mod. Econ. 2015, 6, 1-11. [CrossRef]

47. Arthur, C. Smartphone Explosion in 2014 Will See Ownership in India Pass US. The Guardian. 2014. Available online: https:/ / www.theguardian.com/technology/2014/jan/13/smartphone-explosion-2014-india-uschina-firefoxos-android (accessed on 7 December 2015).

48. eMarketer Smartphone Users Worldwide. Available online: http://www.emarketer.com/Article/ Smartphone-Users-Worldwide-Will-Total-175-Billion-2014/1010536 (accessed on 7 December 2015).

49. Hayes, D. A Practical Guide to Computer Forensics Investigations; Pearson: London, UK, 2014.

50. Farjamfar, A.; Abdullah, M.T.; Mahmod, R.; Udzir, N.I. A review on mobile device's digital forensic process models. Res. J. Appl. Sci. Eng. Technol. 2014, 8, 358-366.

51. Jang, Y.-J.; Kwak, J. Digital forensics investigation methodology applicable for social network services. Multimed. Tools Appl. 2015, 74, 5029-5040. [CrossRef]

52. Ferrara, E.; De Meo, P.; Catanese, S.; Fiumara, G. Detecting criminal organizations in mobile phone networks. Expert Syst. Appl. 2014, 41, 5733-5750. [CrossRef]

53. Palmer, G. A Road Map for Digital Forensic Research. In Proceedings of the 2001 Digital Forensics Research Workshop (DFRWS 2004), Orlando, FL, USA, 11-13 August 2004.

54. Paraben Paraben. Available online: https://www.paraben.com/device-seizure.html (accessed on 7 December 2015).

55. Oxygen Oxygen Forensics. Available online: http://www.oxygen-forensic.com/en/ (accessed on 7 December 2015).

56. Cellebrite Mobile Foresics-Delivering Mobile Expertise. Available online: http://www.cellebrite.com/ Mobile-Forensics (accessed on 7 December 2015).

57. Knight, R. National Security or Consumer Privacy? A Question Even Siri Couldn't Answer. Univ. Cin. Intell. Prop. Comput. Law J. 2016, 1, 1-13.

58. Howe, J. The Rise of Crowdsourcing. Wired Mag. 2006, 14, 1-5.

59. Kantar Smarphone OS Market Share. Available online: http://www.kantarworldpanel.com/global/ smartphone-os-market-share/intro (accessed on 7 December 2015).

60. Laplume, A.; Anzalone, G.C.; Pearce, J.M. Open-source, self-replicating 3-D printer factory for small-business manufacturing. Int. J. Adv. Manuf. Technol. 2016, 85, 633-642. [CrossRef]

61. Stratasys FDM Technology, About Fused Deposition Modeling Stratasys. Available online: http://www. stratasys.com/3d-printers/technologies/fdm-technology (accessed on 7 December 2015). 
62. Masood, S.H. Intelligent rapid prototyping with fused deposition modelling. Rapid Prototyp. J. 1996, 2, $24-33$. [CrossRef]

63. GitHub. Available online: https://github.com/ (accessed on 11 May 2016).

64. The World Commission on Environment and Development. Our Common Future; Oxford University Press: Oxford, UK, 1987; Volume 154.

65. Liu, L. Sustainability: Living within one's own ecological means. Sustainability 2009, 1, 1412-1430. [CrossRef]

66. Ljungberg, L.Y. Materials selection and design for development of sustainable products. Mater. Des. 2007, 28, 466-479. [CrossRef]

67. Nozick, L.K.; Turnquist, M.A. Inventory, transportation, service quality and the location of distribution centers. Eur. J. Oper. Res. 2001, 129, 362-371. [CrossRef]

68. Paris Climate Change Conference-November 2015. Available online: http://unfccc.int/meetings/paris_ nov_2015/meeting/8926.php (accessed on 7 July 2016).

69. International Energy Agency. World Energy Outlook 2013; International Energy Agency: Paris, France, 2013.

70. Pisello, A.L.; Castaldo, V.L.; Rosso, F.; Piselli, C.; Ferrero, M.; Cotana, F. Traditional and Innovative Materials for Energy Efficiency in Buildings. Key Eng. Mater. 2016, 678, 14-34. [CrossRef]

71. Haines, A.; Kovats, R.S.; Campbell-Lendrum, D.; Corvalan, C. Climate change and human health: Impacts, vulnerability and public health. Public Health 2006, 120, 585-596. [CrossRef] [PubMed]

72. Boons, F.; Lüdeke-Freund, F. Business models for sustainable innovation: State-of-the-art and steps towards a research agenda. J. Clean. Prod. 2013, 45, 9-19. [CrossRef]

73. Remer, D.S.; Nieto, A.P. A compendium and comparison of 25 project evaluation techniques. Part 1: Net present value and rate of return methods. Int. J. Prod. Econ. 1995, 42, 79-96. [CrossRef]

74. Ferrin, B.G.; Plank, R.E. Total Cost of Ownership Models: An Exploratory Study. J. Supply Chain Manag. 2002, 38, 18-29. [CrossRef]

75. Shaikh, M.; Cornford, T. Framing the Conundrum of Total Cost of Ownership of Open Source Software. Open Source Syst. Grounding Res. 2011. [CrossRef]

76. Shaikh, M.; Cornford, T. Total Cost of Ownership of Open Source Software: A Report for the UK Cabinet Office Supported by OpenForum Europe; London School of Economics and Political Science: London, UK, 2011.

77. Makerbot 3D Printing Resources and Tools MakerBot. Available online: http://www.makerbot.com/ (accessed on 7 December 2015).

78. TierTime. Available online: http://www.tiertime.com/en/ (accessed on 7 December 2015).

79. Cappa, F.; Facci, A.L.; Ubertini, S. Proton exchange membrane fuel cell for cooperating households: A convenient combined heat and power solution for residential applications. Energy 2015, 90, 1229-1238. [CrossRef]

80. Zadeh, S.; Hunt, D.; Lombardi, D.; Rogers, C. Shared Urban Greywater Recycling Systems: Water Resource Savings and Economic Investment. Sustainability 2013, 5, 2887-2912. [CrossRef]

81. Damodaran, A. Investment Valuation: Tools and Techniques for Determining the Value of Any Asset; John Wiley \& Sons: Hoboken, NJ, USA, 2012; Volume 666.

82. Willassen, S. Forensic analysis of mobile phone internal memory. In Advances in Digital Forensics; Springer: Berlin, Germany, 2005; pp. 191-204.

83. Chun, W.-S.; Park, D.-W. A study on the forensic data extraction method for sms, photo and mobile image of google android and windows mobile smart phone. In Convergence and Hybrid Information Technology; Springer: Berlin, Germany, 2012; pp. 654-663.

84. Grispos, G.; Storer, T.; Glisson, W.B. A comparison of forensic evidence recovery techniques for a windows mobile smart phone. Digit. Investig. 2011, 8, 23-36. [CrossRef]

85. Schaltegger, S.; Freund, F.L.; Hansen, E.G. Business cases for sustainability: The role of business model innovation for corporate sustainability. Int. J. Innov. Sustain. Dev. 2012, 6, 95. [CrossRef]

86. Arcese, G.; Lucchetti, M.; Merli, R. Social Life Cycle Assessment as a Management Tool: Methodology for Application in Tourism. Sustainability 2013, 5, 3275-3287. [CrossRef]

(C) 2016 by the authors; licensee MDPI, Basel, Switzerland. This article is an open access article distributed under the terms and conditions of the Creative Commons Attribution (CC-BY) license (http://creativecommons.org/licenses/by/4.0/). 